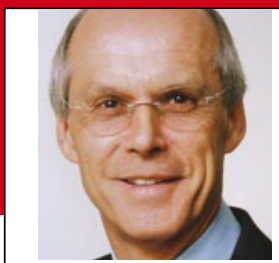

Prof. Dr. med. H. S. FüeßI

Isar-Amper-

Klinikum,

KI. München-Ost,

Haar

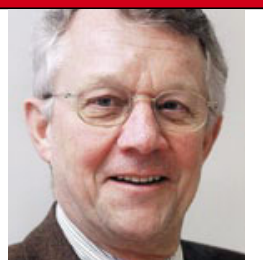

Prof. Dr. med. H. Holzgreve

Internist,

Kardiologische

Praxis, München

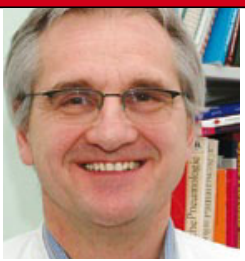

Prof. Dr. med.

M. Griese

Haunersches

Kinderspital,

München

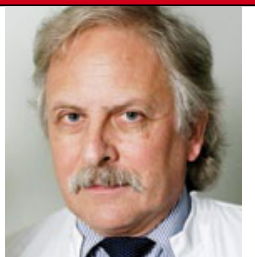

Prof. Dr. med. H.-C. Diener

Klinik für

Neurologie,

Essen

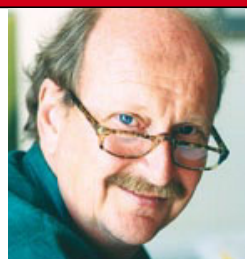

Prof. Dr. med.

E. Ernst

Peninsular

Medical School,

University

of Exeter/UK

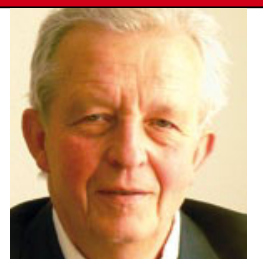

Prof. Dr. med. K. Malberg

Immunologie,

Dresden-

Loschwitz

\title{
Neue Daten zu Nebenwirkungen häufig verordneter Medikamente
}

\section{Drei große Studien erlauben Aus- sagen zu vielfach diskutierten Problemen von Angiotensin-Re- zeptorblockern, Betablockern und Protonenpumpenhemmern (PPI).}

— 37 randomisierte Studien mit 147020 Probanden zeigen, dass unter Angiotensin-Rezeptorblockern im Vergleich mit Placebo und anderen Medikamenten in gleicher Indikation Herzinfarkte und Angina pectoris nicht häufiger, und Schlaganfälle, Herzinsuffizienz sowie neu entdeckte Diabetesfälle sogar seltener sind.

Short et al. werteten schottische Datenbanken von 5977 COPD-Patienten

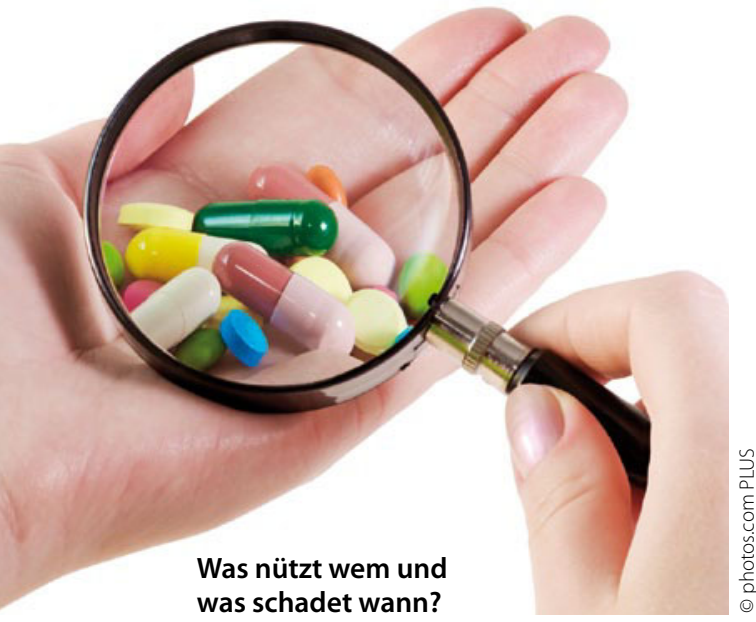

jenseits des 50. Lebensjahres aus. Die Patienten, die Betablocker ( $88 \%$ davon kardioselektiv) erhielten, hatten - unabhängig von kardiovaskulären Begleiterkrankungen - eine geringere Gesamtmortalität, seltener Exazerbationen und weniger Krankenhausaufenthalte. Die Lungenfunktion wurde nicht beeinträchtigt.

Aus einer dänischen Datenbank wurde der Verlauf aller Patienten, die zwischen 1997 und 2006 einen ersten, akuten Herzinfarkt mindestens 30 Tage überlebten, überprüft. Es erlitten 3366 mit ASS behandelte Patienten innerhalb eines Jahres einen Reinfarkt bzw. einen Schlaganfall oder verstarben aus kardio- vaskulärer Ursache. Wenn ASS mit einem PPI kombiniert wurde, war der kombinierte Endpunkt um das 1,45bzw. 1,61-fache häufiger.

\section{- S. Bangalore et al.}

Angiotensin receptor blockers and risk of myocardial infarction: meta-analyses and trial sequentiel analyses of 147020 patients from randomised trials. Brit. Med. J. 342 (2011) 1010 - P. M. Short et al.

Effect of $ß$ blockers in treatment of chronic obstructive pulmonary disease: a retrospective cohort study. Brit. Med. J. 342 (2011) d2549

- M. Charlot et al.

Proton pump inhibitor use and risk of adverse cardiovascular events in aspirin treated patients with first time myocardial infarction: nationwide propensity score matched study. Brit. Med. J. 342 (2011) 1135

\section{Kommentar}

Die drei Studien führen eine lange, teils höchst kontroverse Diskussion fort. Am einfachsten scheint die Bewertung der Angiotensin-Rezeptorblocker: Es dürften nun alle Bedenken gegen deren kardiovaskuläre Sicherheit ausgeräumt sein.

Schwieriger bleibt die Bewertung der Betablocker bei COPD, weil viele Ärzte schon einmal Lungenfunktionsverschlechterungen bei ihren Patienten erlebt haben und man bezweifeln darf, ob diese in Datenbanken zuverlässig erfasst werden. Immerhin ist denkbar, dass bei COPD-Patienten mit kardialen Erkrankungen der Nutzen der Betablocker größer ist als ihr Schaden. Allerdings waren die Ergebnisse bei Patienten mit und ohne kardiale Begleiterkrankung gleich. Die Diskussion um die Wechselwirkungen zwischen ASS und Protonenpumpenhemmern ist sicher nicht abgeschlossen. Doch werden Bedenken gegen die rein prophylaktische Kombination beider Medikamente verstärkt.

H. HOLZGREVE " 